\title{
Investigating the factors affecting the internet of things (IOT) adoption model -an exploratory study in Egypt
}

\author{
Ghada Zaky \\ Prof. Ayman Shawky \\ Prof. Mohamed A. Ragheb \\ Arab Academy for Science, Technology \& Maritime Transport \\ Alexandria, Egypt
}

\begin{abstract}
Keywords
Internet of Things (IOT), Extended Unified Theory of Acceptance and Use of Technology (UTAUT2), Adoption, Security Concern, Privacy concern.
\end{abstract}

\begin{abstract}
Purpose: This study aims to investigate the factors that affect developing countries especially Egyptian users to adopt IOT Applications/devices, and to what extent those variables affect the overall attitude towards, behavioral intentions and actual usage of IOT applications/devices. Moreover, to develop an extended adoption model by integrating the security concern and privacy concern in UTAUT2 model.

Design/Methodology: a descriptive quantitative approach was adopted, and a comprehensive research model was adapted from literature and then tested via an online questionnaire.

Results/Findings: The findings revealed that Effort Expectancy, Facilitating Conditions and Security Concern all have a significant positive effect on the overall intention towards using IOT applications/devices in Egypt.

Theoretical and practical implications: The Internet of Things (IOT) has emerged as an innovative computing technology destined to optimize business operations and create new products and services. IOT enable the devices to communicate and integrate with one another to collect, exchange, and make data accessible through the Internet. It is projected that by 2025, over 50 billion devices will be connected to the IOT network, reaching a market value of up to $\$ 11$ trillion. This study adapted the Extended Unified Theory of Acceptance and Use of Technology (UTAUT2) as the theoretical framework and its findings contribute to the literature by adding security and privacy concerns as new predictor variables.

This contributes theoretically to the current literature by providing meaningful insights into the main factors that affect using IOT Applications/Devices in developing countries specially Egypt. This study's conceptual effort provided an overall overview of how IOT users arrive at choosing (or not choosing) to use IOT applications/devices. Additionally, the analytic effort of this study provided a holistic assessment of the role of each variable. One critical question in this case is whether industrial leaders should assign an equal number of resources to each variable or not. By assessing the significance of each variable, the researcher attempted to clarify the comparative importance of each variable in forecasting purchase intentions and decisions to use IOT applications/devices.
\end{abstract}

\section{Introduction}

The Internet of Things (IOT) is a group of Internets connected smart devices (Herold, 2015). Smart devices are wireless embedded devices which are capable of collecting, exchanging, saving, processing, and make the data accessible to users (Bojanova, Hurlburt, \& Voas, 2014). The smart devices are currently being used in creative ways to improve the lives of their users and advance society. IOT has many applications in the modern world that span from smart homes, education, healthcare, wearables, agriculture, and industrial automation to even cover large areas like entire smart cities (Abdel-Basset, Manogaran, Mohamed, \& Rushdy, 2018). despite the progress made over the years, the technology was not widely adopted by most consumers as expected (Nordrum, 2016). Gartner (2017) and International Data Corporation (IDC) (2015 estimated the economic growth to exceed the trillion-dollar mark by 2020, but Lueth (2018) and Kaki (2018) stated that the increase only reached between $\$ 130$ and $\$ 150$ billion in 2018. As a result of the differences between expectation and reality, it is evident that IO technology will 
not exceed the trillion-dollar or the trillion devices by 2020 since the real number in the third quarter of 2016 is somewhere closer to 6.4 billion devices (Nordrum, 2016).

More recently new pressures on companies to adopt the IOT technologies are originating from various stakeholders: partners, competitors, customers, and suppliers. Such external pressures, even ahead of internal performance improvements, represent the main stimulus for companies to adopting the IOT. Moreover, the IOT adoption has recently been supported by many national government policies; for instance, the Italian government awards companies which adopt the so-called "Industry 4.0 " technologies with tax credit and further incentives (Ammirato et al., 2018). Therefore, this research comes to investigate the factors affecting the IOT adoption in the Egyptian Society as one example of the developing countries.

The statistical analysis of the variables affecting the adoption of Internet of Things Technology was conducted to explore the correlation between variables and the tendency of adoption by consumers. The adoption/rejection tendency and thus the intention of use were identified based on the classification of the variables based on theoretical adoption techniques by Venkatesh, Thong, and $\mathrm{Xu}$ (2012). Findings from the study may help Information Technology (IT) developers as well as consumers and industry leaders by support in the design, education, developing and distribution of IOT innovations, and to have plan in place that promote and provide IOT designs that follow the hierarchy of needs of consumers, and therefore, IOT developers can use the information to create innovation based on consumer desires and needs.

Although the technology shows great potential, there are many security and privacy issues and concerns with the IOT which may impact adoption (Atzori, Iera, \& Morabito, 2010). The overall goal of this study also is to quantitatively measure the impact that security and privacy awareness has on the adoption of the IOT.

Adoption of technology has been studied for decades. The extended unified theory of acceptance and use of technology (UTAUT2) will be used as the base model of this study (V. Venkatesh 2012). This model has been cited more than a thousand times and has stood the test of time. A new construct will be added to the model, that of security concern and privacy concern. The new extended model will be tested to determine how well it measures the correlation of the constructs involved in technology acceptance in Egypt.

IOT is one of the trending technologies nowadays and IOT adoption is not an easy issue, especially in the developing countries. In addition, few researches had discussed IOT adoption especially from the quantitative vision of the technology rather than the qualitative opinion. Therefore, this research comes to fill such gap in the literature and study IOT adoption and the factors affecting it. This research is divided into several sections, where the first one is represented in the current introduction for the research. The second section presents a review of the previous studies related to IOT adoption and the factors that could affect it. The third section presents the research methodology for the current research, while the fourth section displays the results and findings for the empirical study. Finally, a conclusion is derived for this research in the fifth section.

\section{Literature Review}

The Unified Theory of Acceptance and Use of Technology (UTAUT) has been developed in 2003 by Venkatesh, Morris, Davis. This theory is based on a combination of the eight important technology acceptance theories and various models that arise from different research areas such as information technology systems, sociology, and psychology, These models are the Theory of Reasoned Actions (TRA), Theory of Planned Behavior (TPB), Technology Acceptance Model (TAM), Model of Personal Computer Utilization (MPCU), Memory Module (MM), Systems and Computer Technology (SCT), Extended Technology Acceptance Model (TAM2), and Diffusion of Innovation (DOI). it aims to explain user intentions to use technology and increase usage behavior. Each model of the mentioned ones attempted to expect and explain user behavior using various independent variables. A unified model was created based on the conceptual and empirical similarities across these models. The theory holds that four key constructs (performance expectancy, effort expectancy, social influence, and facilitating conditions) are direct determinants of usage intention and behavior.

In 2005 this UTAUT theory resulted in the publication of a widely used model and validated measurement tool (Sundaravej, 2005), and is widely applied in research in technology acceptance 
regarding several wireless IT applications such as mobile banking (Wang \& Wang, 2010); (AbuShanab \& Pearson, 2007); (Cheng, Song, \& Qian, 2008), using of mobile paying methods in public transport (De Hoog, 2014) or the usage of Radiofrequency ID-technology in E-health applications (Spil \& Schuring, 2006).

Alshehri et al. (2013) conducted a survey and collected data from 400 respondents, to find the factors that affect the acceptance of technology services in KSA using UTAUT model. It was concluded that Performance Expectancy, Effort Expectancy, and Facilitating Condition have positive impact on user intention to use technology services. However, Social Influence was found to be insignificant.

Between 2005 and 2012 several extensions to the basic UTAUT model were made on order to enhance the model's predictive capacity and to make it specific for a particular markets and innovations. This resulted in the publication of an enhanced UTAUT2 model which was especially designed for the consumer acceptance of ICT innovations. (Venkatesh, Thong, \& Xu, 2012). This UTAUT2 model contains three extra factors on top of the original UTAUT model: Habit, Hedonic motivations, and Price value. An empirical support was provided for the applicability of UTAUT2 to the consumer context via a two-stage online survey of 1,512 mobile Internet consumers. It was shown that in the context of consumers' use of technology, the effects of hedonic motivation, price value, and habit are strong and important. The variance explained in both behavioral intention (74\%) and technology use (52\%) are substantial, compared to the baseline UTAUT that explained $56 \%$ and $40 \%$ of the variance in intention and use, respectively. Overall, it was confirmed the important roles of hedonic motivation, price value, and habit in influencing technology use in UTAUT2, which is tailored to the context of consumer acceptance and use of technology (Venkatesh et al. (2013)).

Figure1 shows the extended UTAUT2 Model which is explained in seven main constructs which interpret the attitude towards the use of technology. These factors are expressed in two groups of variables, where the first group represent the original UTAUT variables (performance expectancy, effort expectancy, social influence, and facilitating conditions) and the second group represents three new variables (Hedonic Motivation, Price Value and Habit).

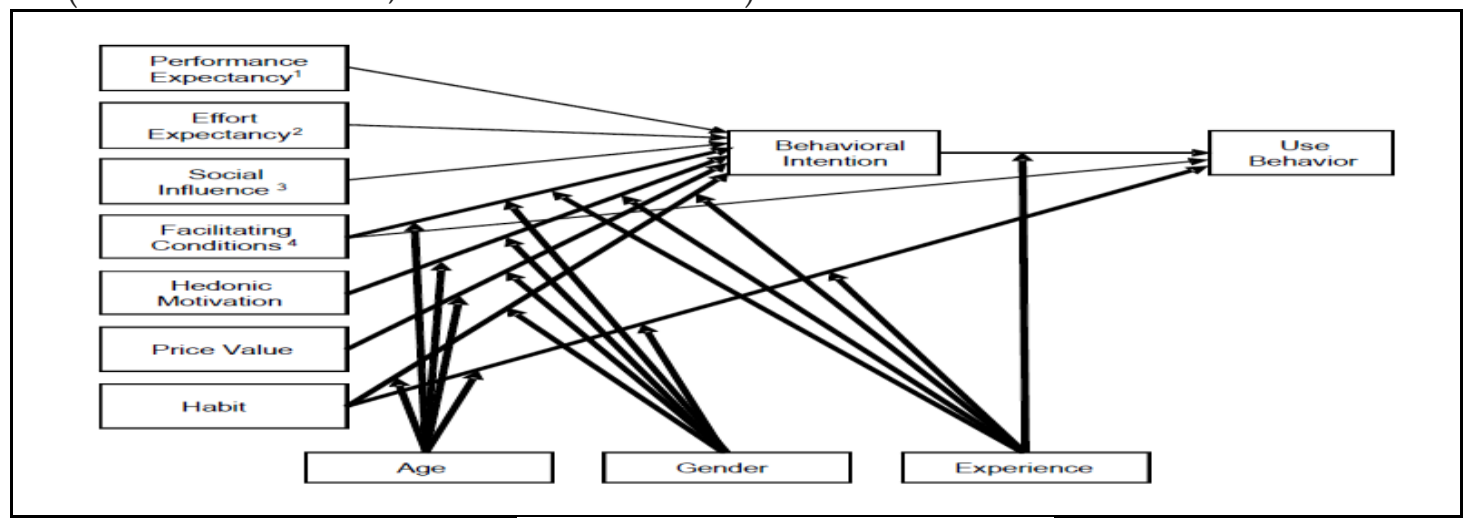

Figure1 shows the UTAUT2 model

Also, other researchers extended the original UTAUT model with potential predictive factors. Examples of these factors are: Trust (Gefen, Karahanna, \& Straub, 2003), Privacy (Min, Ji, \& Qu, 2008), Concerns for the natural environment (Letiklane, 2015) etc.

Thomas et al. (2013) applied a web survey on the students at the University of Guyana. The conducted survey was in a developing country while the UTAUT model and most M-Learning studies are based on data collected in Western contexts. Resources are generally limited in developing countries and under such conditions; it is likely that the facilitating conditions affect adoption. It was also claimed that Attitude is not included in the original UTAUT model, but it has the largest effect on behavioral intention. Attitude towards the use of technologies for learning was hence the most important driver of adoption.

El-Masri and Tarhini (2017) explored the UTAUT2 model to determine the key variables; hedonic motivation, price value and habit that influence the adoption of e-learning system at universities in developing (Qatar) and developed (USA) countries. So, the result was shown that the hedonic motivation, 
price value, and habit influence in behavioural intention in both cases of developing and developed countries.

Tak and Panwar (2017) tested shopping in India using mobile shopping apps by using (UTAUT2) model to understand the impact and customer's behaviour when using mobile apps for shopping, where it was found that hedonic motivates has a strong impact on customer's behaviour, when customers explore new products while using the app. When see discounts of offers in apps, they directly determine the price and compared it with the benefits of the products this will make them have cost saving. So, it was shown that hedonic motivates and habit have a strong impact and influence on customer intention while using technology, and the price is important indicators when buying online. Moreover, Yuan et al. (2015) proposed that mobiles apps used UTAUT2. The result shows that hedonic motivates, price value and habits have strong impact on technology model when being applied on the mobile apps for health and fitness.

\section{Research Methodology}

The quantitative research method selected was deemed appropriate because the independent and dependent variables were clearly identified, and the statistical outcome produced can aid the researcher in deriving a conclusion.

In order to test the research hypotheses that under this study, the research methodology adopted is based on several issues as illustrated below:

Population and Sample: The target population for this research is considered as the Adult Egyptian persons from all areas of profession and education, since obtaining data about all members of a population is not available and very difficult (Fowler, 2013), the sampling frame for this research could not be identified and accordingly a probability sampling is not obtained. Therefore, a convenient sampling technique was used as respondents were selected from who agreed to respond to the online questionnaire. A total number of 573 were considered in the study.

Data Collection: The data collection process is handled through the development of a questionnaire. The adoption of this data collection method was due to the need to measure the focal constructs of the model, as well as the extensive use of survey methodology in previous studies. The questionnaire was adopted from the studies of (R. MĄCIK (2017), Yonghee Kim (2015), Chin-Lung Hsu (2016), Bunmi Samuel (2018), Venkatesh (2012)).

Research Framework and Hypotheses: The proposed framework was introduced in the following Figure2, where it could be observed that Performance Expectancy (PE), Effort Expectancy (EE), Social Influence (SI), Facilitating Conditions (FC), Hedonic Motivation(HM), Price Value (PV), Habit(HB), Security Concern (SC) and Privacy Concern (PC), were considered as the independent variables, while Use Behavior(UB) of IOT is considered as the dependent variable, and Behavioral Intention to Adopt (IOT) is considered to be the meditator that meditate the relation between the independent and depended variables.

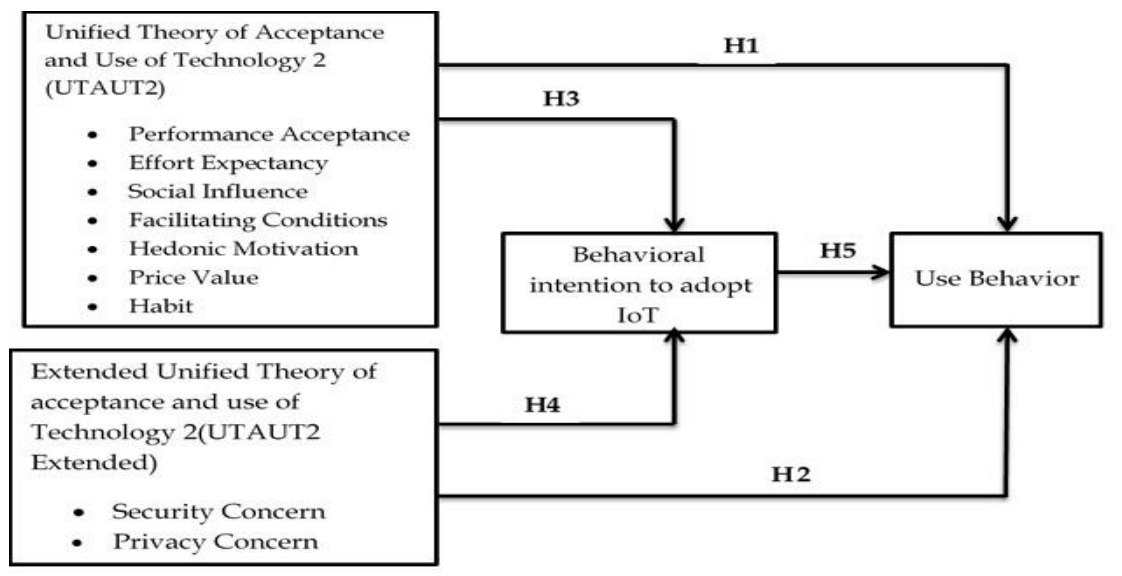

Figure 2: The research model

Accordingly, the research hypotheses could be formulated as follows: 
$\mathrm{H}_{1}$ : Unified theory of acceptance \& use of a technology 2(UTAUT2) has a significant impact on the use behavior (UB).

H1.a: Performance expectancy (PE) has a significant impact on the use behavior (UB).

H1.b: Effort expectancy (EE) has a significant impact on the use behavior (UB).

H1.c: Social influence (SI) has a significant impact on the use behavior (UB).

H1.d: Facilitating Conditions (FC) has a significant impact on the use behavior (UB).

H1.e: Hedonic Motivation (HM) has a significant impact on the use behavior (UB).

H1.f: Price Value (PV) has a significant impact on the use behavior (UB).

H1.g: Habit (HB) has a significant impact on the use behavior (UB).

H2: Unified theory of acceptance \& use of a technology 2 extended (UTAUT2) has a significant impact on the use behavior (UB).

H2. a: Security concern (SC) has a significant impact on the use behavior (UB).

H2.b: Privacy concern (PC) has a significant impact on the use behavior (UB).

H3: Behavioral Intention to Adopt (IOT) mediates the relationship between Unified theory of acceptance \& use of a technology 2(UTAUT2) \& the use behavior (UB).

H4: Behavioral Intention to Adopt (IOT) mediates the relationship between Unified theory of acceptance \& use of a technology 2 extended (UTAUT2) \& the use behavior (UB).

H5: Behavioral Intention to Adopt (IOT) has a significant impact the use behavior (UB).

An online survey with 45 questions were posed to respondents. These questions are related to 11 different variables: Performance Expectancy (PE), Effort Expectancy (EE), Social Influence (SI), Facilitating Conditions (FC), Hedonic Motivation (HM), Price Value (PV), Habit (HB), Security Concern (SC) and Privacy Concern (PC), Behavioral Intention to Adopt (IOT), Use Behavior.

The following section will investigate the research hypotheses proposed above using correlation analysis and Structural Equation Modeling (SEM). Thus, both; SPSS version 26 and AMOS version 25 statistical packages, are used to test the research hypotheses, the regression analysis and SEM were fitted to predict research model.

\section{Results and Findings \\ Data Testing}

Table 1 shows the Validity and Reliability analysis. It could be observed that the values of KMO, AVE, Cronbach's Alpha, and Factor Loading are within the acceptance level. The overall reliability for the measure is inacceptable range.

\section{Descriptive Analysis}

the respondent profiles, it was observed that the percentage of age group from 31 to 40 years is higher than other age groups in the research sample as it got $43.5 \%$, also $59.5 \%$ of the sample male and $40.5 \%$ female, regarding the education $1.2 \%$ percentage are in high school education, $18.5 \%$ have bachelor's degree, $43.5 \%$ have MBA degree and 33.3\% PhD holders.

Table 2 shows the Mean and Standard Deviation for Research variables. It could be observed that the mean and the frequencies of most responses are in the agreement zone, and also all means are nearly close to each other. As it could be observed that the highest mean value was for Effort Expectancy (EE)and the least one was for Habit. 


\begin{tabular}{|c|c|c|c|c|c|}
\hline Variables & KMO & AVE & $\begin{array}{l}\text { Cronbach's } \\
\text { Alpha }\end{array}$ & Item & $\begin{array}{l}\text { Factor } \\
\text { Loading }\end{array}$ \\
\hline \multirow{3}{*}{ Performance Expectancy (PE) } & \multirow{3}{*}{0.655} & \multirow{3}{*}{0.60331} & \multirow{3}{*}{0.673} & PE1 & \\
\hline & & & & PE2 & 0.881 \\
\hline & & & & PE3 & 0.898 \\
\hline \multirow{3}{*}{ Effort Expectancy (EE) } & \multirow{3}{*}{0.622} & \multirow{3}{*}{0.583276} & \multirow{3}{*}{0.637} & EE1 & 0.687 \\
\hline & & & & EE2 & 0.776 \\
\hline & & & & EE3 & 0.822 \\
\hline \multirow{3}{*}{ Social Influence (SI) } & \multirow{3}{*}{0.677} & \multirow{3}{*}{0.661178} & \multirow{3}{*}{0.74} & SI1 & 0.641 \\
\hline & & & & SI2 & 0.872 \\
\hline & & & & $\begin{array}{l}\text { SI3 } \\
\text { SI4 }\end{array}$ & $\frac{0.866}{0.6}$ \\
\hline \multirow{4}{*}{ Facility Conditions (FC) } & \multirow{4}{*}{0.697} & \multirow{4}{*}{0.545022} & \multirow{4}{*}{0.606} & FC1 & 0.78 \\
\hline & & & & FC2 & 0.861 \\
\hline & & & & FC3 & 0.814 \\
\hline & & & & FC4 & 0.543 \\
\hline Hedonic Motivation (HM) & \multirow{3}{*}{$\frac{0.762}{0.5}$} & 0.580644 & 0.676 & $\begin{array}{l}\text { HM1 } \\
\text { HM2 }\end{array}$ & $\frac{0.762}{0.762}$ \\
\hline \multirow{2}{*}{ Price Value } & & \multirow{2}{*}{0.565504} & \multirow{2}{*}{0.73} & PV1 & 0.752 \\
\hline & & & & PV2 & 0.752 \\
\hline \multirow{3}{*}{ Habit } & \multirow{3}{*}{0.505} & \multirow{3}{*}{0.640979} & \multirow{3}{*}{0.615} & H1 & 0.804 \\
\hline & & & & F12 & 0.797 \\
\hline & & & & $\begin{array}{l}113 \\
14\end{array}$ & $\frac{0.519}{0.584}$ \\
\hline \multirow{4}{*}{ Security Concern } & \multirow{4}{*}{0.605} & \multirow{4}{*}{0.545692} & \multirow{4}{*}{0.567} & SC1 & 0.714 \\
\hline & & & & $\operatorname{sc2}$ & 0.732 \\
\hline & & & & $\mathrm{SC} 3$ & 0.782 \\
\hline & & & & $\mathrm{SC4}$ & 0.725 \\
\hline & & & & PC1 & 0.731 \\
\hline & & & & PC2 & 0.806 \\
\hline & & & & PC3 & 0.654 \\
\hline Privacy Concern & 0.843 & 0.733427 & 0.607 & PC4 & 0.695 \\
\hline & & & & PC5 & 0.7 \\
\hline & & & & PC6 & 0.588 \\
\hline & & & & PC7 & 0.635 \\
\hline Behavioral Intention to adopt (IOT) & 0.505 & 0.537546 & 0.602 & $\begin{array}{l}\text { IOT1 } \\
\text { IOT2 }\end{array}$ & 0.945 \\
\hline Behavioral Intention to adopt (IOT) & & & 0.602 & $\frac{10 T 2}{10 T 3}$ & 0.949 \\
\hline & & & & UBEI I1 & 0.87 \\
\hline Use behavior & 0.87 & 0.69321 & 0.773 & UBEH 2 & 0.889 \\
\hline Overall Reliability & 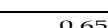 & 0.608 & & UBEI 13 & 0.728 \\
\hline
\end{tabular}

Table 1: Validity and reliability

\begin{tabular}{|l|r|r|r|}
\hline \multicolumn{1}{|c|}{ Variable } & N & Mean & $\begin{array}{r}\text { Std. } \\
\text { Deviation }\end{array}$ \\
\hline Performance Expectancy (PE) & 573 & 3.643 & 0.65006 \\
\hline Effort Expectancy (EE) & 573 & 3.818 & 0.67244 \\
\hline Social Influence (SI) & 573 & 3.452 & 0.70337 \\
\hline Facilitating Conditions (FC) & 573 & 3.38 & 0.58867 \\
\hline Hedonic Motivation & 573 & 3.429 & 0.73876 \\
\hline Price Value (PV) & 573 & 3.521 & 0.70148 \\
\hline Habit & 573 & 3.182 & 0.65129 \\
\hline Security Concern (SC) & 573 & 3.409 & 0.63542 \\
\hline Privacy Concern (PC) & 573 & 3.339 & 0.50506 \\
\hline Behavioral Intention to Adopt (IOT) & 573 & 3.627 & 0.59919 \\
\hline Use Behavior(UB) & 573 & 3.609 & 0.71482 \\
\hline
\end{tabular}

Table 2: Descriptive Analysis for the Research Variables

\section{Normality Testing for the Research Variables}

The result of the analysis shows that none of the variables falls outside the \pm 1 range of skewness and kurtosis in this study. Thus, the data for this study is normal in relation to Skewness and kurtosis (Hair et al., 2006). Table 3 summarizes the skewness and kurtosis for the study 's variables.

\begin{tabular}{|c|c|c|c|c|}
\hline \multirow[b]{2}{*}{ Variable } & \multicolumn{2}{|c|}{ Skewness } & \multicolumn{2}{|c|}{ Kurtosis } \\
\hline & Statistic & Std. Error & Statistic & $\begin{array}{c}\text { Std. } \\
\text { Error }\end{array}$ \\
\hline Performance Expectancy (PE) & $-1.002-$ & 0.187 & 2.463 & 0.373 \\
\hline Effort Expectancy (EE) & $-.968-$ & 0.187 & 2.658 & 0.373 \\
\hline Social Influence (SI) & $-.556-$ & 0.187 & 1.532 & 0.373 \\
\hline Facilitating Conditions (FC) & $-.933-$ & 0.187 & 1.58 & 0.373 \\
\hline Hedonic Motivation & $-.585-$ & 0.187 & 0.854 & 0.373 \\
\hline Price Value (PV) & $-.404-$ & 0.187 & 0.073 & 0.373 \\
\hline Habit & $-.062-$ & 0.187 & 0.911 & 0.373 \\
\hline Security Concern (SC) & $-.988-$ & 0.187 & 2.32 & 0.373 \\
\hline Privacy Concern (PC) & $-1.080-$ & 0.187 & 3.538 & 0.373 \\
\hline Behavioral Intention to Adopt (IOT) & $-.902-$ & 0.187 & 1.682 & 0.373 \\
\hline Use Behavior(UB) & $-.757-$ & 0.187 & 1.485 & 0.373 \\
\hline
\end{tabular}

Table 3: Skewness and Kurtosis of the Variables

Table 4 shows the formal test of normality assumption for the research variables. It could be observed that the research variables are not normally distributed as the P-values are less than 0.05. 


\begin{tabular}{|c|c|c|c|c|c|c|}
\hline \multicolumn{7}{|c|}{$\begin{array}{r}\text { Tests of Normality } \\
\end{array}$} \\
\hline & \multicolumn{3}{|c|}{ Kolmogorov-Smirnova } & \multicolumn{3}{|c|}{ Shapiro-Wilk } \\
\hline & Statistic & df & Sig. & Statistic & df & Sig. \\
\hline $\mathbf{P} \_\mathbf{E}$ & .175 & 573 & .000 & .917 & 573 & .000 \\
\hline $\mathbf{E} \_\mathbf{E}$ & .167 & 573 & .000 & .926 & 573 & .000 \\
\hline S_I & .105 & 573 & .000 & .957 & 573 & .000 \\
\hline F_C & .153 & 573 & .000 & .938 & 573 & .000 \\
\hline H_M & .164 & 573 & .000 & .939 & 573 & .000 \\
\hline PV & .163 & 573 & .000 & .932 & 573 & .000 \\
\hline habit & .119 & 573 & .000 & .971 & 573 & .001 \\
\hline utaut & .097 & 573 & .001 & .905 & 573 & .000 \\
\hline utaut_ext & .140 & 573 & .000 & .901 & 573 & .000 \\
\hline S_C & .187 & 573 & .000 & .921 & 573 & .000 \\
\hline P_C & .128 & 573 & .000 & .935 & 573 & .000 \\
\hline BI & .181 & 573 & .000 & .929 & 573 & .000 \\
\hline & & & & & & \\
\hline
\end{tabular}

\section{Test of Multicollinearity}

Table 4: Formal Testing of Normality

The tolerance values and VIF of this study pointed out absence of multicollinearity problem as seen in table 5 .

\begin{tabular}{|l|r|r|}
\hline \multicolumn{1}{|c|}{ Variable } & Tolerance & \multicolumn{1}{c|}{ VIF } \\
\hline Performance Expectancy (PE) & 0.561 & 1.782 \\
\hline Effort Expectancy (EE) & 0.365 & 2.742 \\
\hline Social Influence (SI) & 0.426 & 2.345 \\
\hline Hedonic Motivation & 0.466 & 2.146 \\
\hline Price Value (PV) & 0.558 & 1.791 \\
\hline Habit & 0.543 & 1.842 \\
\hline Security Concern (SC) & 0.485 & 2.063 \\
\hline Privacy Concern (PC) & 0.499 & 2.002 \\
\hline Behavioral Intention to Adopt (IOT) & 0.563 & 1.776 \\
\hline
\end{tabular}

Table 5: Multicollinearity Test - Tolerance and VIF

\section{Testing Research Hypotheses}

In this section, the hypotheses under study are tested using Regression analysis, stepwise analysis and Path analysis in Amos 25, The results analysis revealed the following:

H1: Unified theory of acceptance \& use of a technology 2(UTAUT2) has a significant impact on the use behavior (UB).

Table 6: Summary of Simple Regression for Unified theory of acceptance \& use of a technology 2(UTAUT2) Predicting the use behavior (UB) - $(\mathrm{N}=573)$

\begin{tabular}{|c|c|c|c|}
\hline Variable & $\mathbf{B}$ & SE B & $\mathbf{B}$ \\
\hline (Constant) & 0.715 & 0.325 & \\
\hline Utaut2 & 0.832 & 0.093 & 0.572 \\
\hline $\mathbf{R}^{2}$ & & .327 & \\
\hline F value $(1,572)$ & & 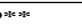 & \\
\hline
\end{tabular}

To test the secondary hypothesis stepwise regression analysis conducted and the test revealed the following:

Table 7: Summary of Stepwise Regression for Unified theory of acceptance \& use of a technology 2(UTAUT2) Dimensions Predicting the use behavior (UB) - (N=573)

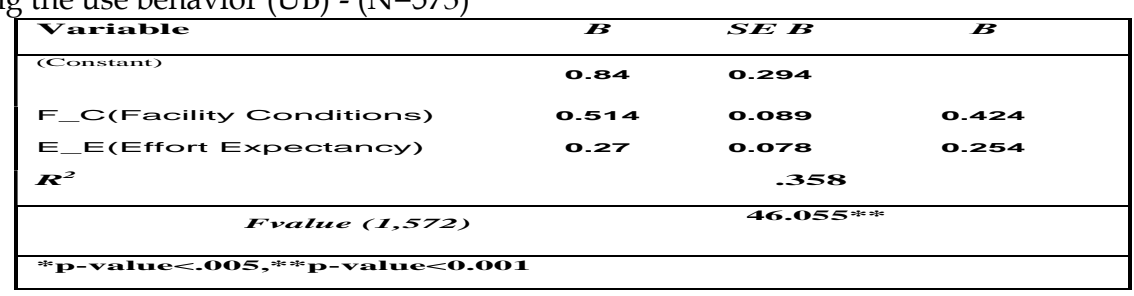

As mentioned in table (7) a significant regression equation was found ( $\mathrm{f}(1,572)=46.055, \mathrm{p}<0.05$, with R2 of $35.8 \%$, the results revealed that only: facility conditions $\left(B=0.514^{*}, p\right.$-value $\left.<0.05\right) \&$ effort expectancy $(B=0.27$, p-value $<0.05)$ positively affects the customers use behaviors. which means accepting the 2nd \& 4th secondary hypothesis, while regarding the other factors the stepwise regressions removed them from the model due to their insignificant effects. And the regression equation can be presented as follows: 
$\mathrm{UB}=0.84-0.514$ F_E (Facility Conditions) + 0.27 E_E (Effort Expectancy)

H2: Unified theory of acceptance \& use of a technology 2 extended (UTAUT2) has a significant impact on the use behavior (UB).

Table 8: Summary of Simple Regression for Unified theory of acceptance \& use of a technology 2(UTAUT2) extended Predicting the use behavior (UB) - (N=573)

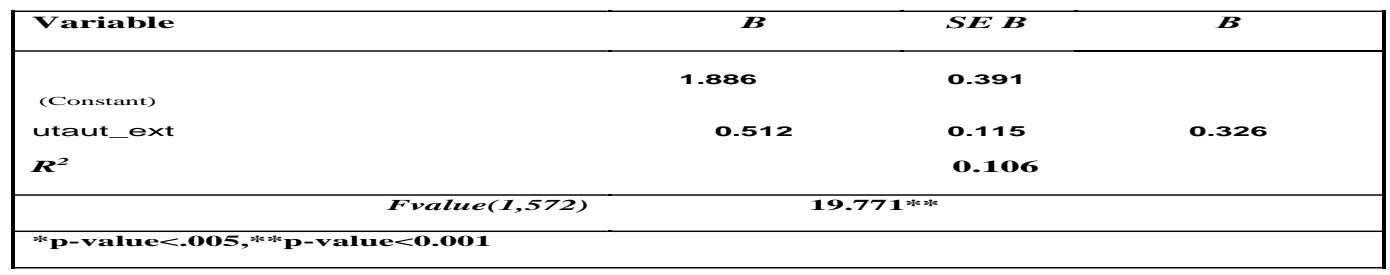

As mentioned in table (8) a significant regression equation was found ( $\mathrm{f}(1,572)=19.771, \mathrm{p}<0.05$, with R2 of $10.6 \%$, the results revealed that Unified theory of acceptance \& use of a technology 2 extended (UTAUT2) $(B=.0 .512 *$, p-value $<0.05)$ has appositive significant impact on the use behavior (UB). which means that UTAUT2-extended predicting the change in use behavior by $10.6 \%$. which means accepting the 2nd main hypothesis and the regression equation can be presented as follows:

$\mathrm{UB}=1.886+0.512$ (UTAUT2) ext

To test the secondary hypothesis regression analysis conducted and the test revealed the following:

Table 9: Summary of Stepwise Regression for Unified theory of acceptance \& use of a technology 2(UTAUT2) extended dimensions Predicting the use behavior (UB) - (N=573)

\begin{tabular}{|llll|}
\hline Variable & $B$ & SE B & B \\
\hline (Constant) & 1.589 & 0.257 & \\
S_C(Security_Concern) & 0.593 & 0.074 & 0.527 \\
$R^{2}$ & & 0.277 & \\
\hline Fvalue(1,572) & $63.746^{* * * *}$ & & \\
\hline${ }^{*}$ P-value<.005,***)-value<0.001 & & & \\
\hline
\end{tabular}

As mentioned in table (9) a significant regression equation was found $(\mathrm{f}(1,572)=63.746, \mathrm{p}<0.05$, with $\mathrm{R} 2$ of $0.277 \%$, the results revealed that only: security concern $\left(B=0.593^{*}\right.$, p-value $\left.<0.05\right)$ positively affects the customers use behaviors. which means accepting the $1^{\text {st }}$ secondary hypothesis, while regarding the other factors the stepwise regressions removed them from the model due to their insignificant effects. And the regression equation can be presented as follows:

UB $=1.589+0.593$ S_C (Security_Concern)

H3: Behavioral Intention to Adopt (IOT) mediates the relationship between Unified theory of acceptance \& use of a technology 2(UTAUT2) \& the use behavior (UB).

Table 10: Summary of the mediation analysis of Behavioral Intention to Adopt (IOT) - $(\mathrm{N}=573)$

\begin{tabular}{|c|c|c|c|c|c|c|c|}
\hline \multirow[b]{2}{*}{ Effect } & \multirow[b]{2}{*}{ Variables } & \multicolumn{3}{|r|}{ UTAUT2 } & \multicolumn{3}{|c|}{ UTAUT2-ext } \\
\hline & & $\begin{array}{r}\text { Lower } \\
\text { C.I. }\end{array}$ & $\begin{array}{r}\text { Upper } \\
\text { C.I. }\end{array}$ & p-value & $\begin{array}{r}\text { Lower } \\
\text { C.I. }\end{array}$ & $\begin{array}{r}\text { Upper } \\
\text { C.I. }\end{array}$ & p-value \\
\hline \multirow[b]{2}{*}{ 腒寻 } & BI & -0.037 & 0.395 & 0.198 & 0.432 & 0.819 & 0.004 \\
\hline & UB & 0.517 & 1.105 & 0.004 & -0.42 & 0.226 & 0.575 \\
\hline \multirow[b]{2}{*}{ 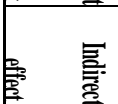 } & BI & 0 & $\mathrm{O}$ & $\cdots$ & $\mathrm{O}$ & 0 & $\cdots$ \\
\hline & UB & -0.012 & 0.083 & 0.338 & -0.017 & 0.221 & 0.158 \\
\hline
\end{tabular}

As mentioned in Table 10 the results indicate that there is an insignificant direct effect of Unified theory of acceptance \& use of a technology 2(UTAUT2) on the user behavior (95\% C.I. (-0.037, 0.395), p-value $=.0 .198)$, also there is no indirect effect of the (UTAUT2 through (BI) $(95 \%$ C.I. $(-0.012,0.083)$, pvalue $=0.338$, therefore the Behavioral Intention to Adopt (IOT) doesn't mediates the relationship between Unified theory of acceptance \& use of a technology 2(UTAUT2) \& the use behavior (UB)., which leads to reject the 3rd hypothesis.

H4: Behavioral Intention to Adopt (IOT) mediates the relationship between Unified theory of acceptance \& use of a technology 2 extended (UTAUT2) \& the use behavior (UB). 
As mentioned in Table 10 the results indicates that there is an insignificant direct effect of Unified theory of acceptance \& use of a technology 2extended (UTAUT2)on the user behavior (95\% C.I. (-0.42, 0.226), p-value $=0.575$ ), also there is no indirect effect of the (UTAUT2-ext) through (BI) (95\% C.I. $(-0.017$

,0.221 ),p-value $=0.158$, therefore the Behavioral Intention to Adopt (IOT) doesn't mediates the relationship between Unified theory of acceptance \& use of a technology 2(UTAUT2)extended \& the use behavior (UB)., which leads to reject the 4 th hypothesis .

H5: Behavioral Intention to Adopt (IOT) has a statistically significant impact the use behavior (UB).

Table 11: Summary of Regression of Behavioral Intention to Adopt (IOT) Predicting the use behavior (UB) - (N=573)

\begin{tabular}{|c|c|c|c|}
\hline Variable & $\boldsymbol{B}$ & SE B & $\boldsymbol{B}$ \\
\hline (Constant) & 2.194 & 0.322 & \\
\hline $\mathrm{BI}$ & 0.39 & 0.088 & 0.327 \\
\hline $\boldsymbol{R}^{2}$ & & 0.107 & \\
\hline $\begin{array}{c}F \\
\text { value }(1,572)\end{array}$ & 19. & & \\
\hline
\end{tabular}

As mentioned in table 11 a significant regression equation was found $(\mathrm{f}(1,572)=19.884, \mathrm{p}<0.05$, with $\mathrm{R} 2$ of $10.7 \%$, the results revealed that behavioral intention to adopt $(\mathrm{IOT})\left(\mathrm{B}=.39^{*}, \mathrm{p}\right.$-value $\left.<0.05\right)$ has appositive significant impact on the use behavior (UB). which means that IOT predicting the change in use behavior by $10.7 \%$. which means accepting the 5 th main hypothesis and the regression equation can be presented as follows:

$\mathrm{UB}=2.194+0.39(\mathrm{IOT})$

Table 12: SEM fit indices

\begin{tabular}{|l|l|l|}
\hline Measure & \multicolumn{1}{|c|}{ Threshold } & \multicolumn{1}{|c|}{ Observed values } \\
\hline Chi-square/df (Cmin/df) & $<3$ good; sometimes permissible & 1.33 \\
\hline p-value for the model & $>0.05$ & 0.305 \\
\hline CFI & $>.95$ great; $>0.90$ traditional; $>0.80$ sometimes permissible & 0.921 \\
\hline GFI & $>.90$ & 0.920 \\
\hline AGFI & $>0.80$ & 0.893 \\
\hline RMSEA & $<0.05$ good,0.5-0.10 moderate; $>0.10$ bad & 0.042 \\
\hline
\end{tabular}

The model fit indices: $\mathrm{CMIN} / \mathrm{DF}=1.33, \mathrm{GFI}=0.920, \mathrm{CFI}=0.921, \mathrm{AGFI}=0.893$, and $\mathrm{RMSEA}=0.042$ are all within their acceptable levels. The SEM model conducted for the effect of Unified theory of acceptance \& use of a technology 2 extended (UTAUT2) on customer loyalty is illustrated in the following figure.

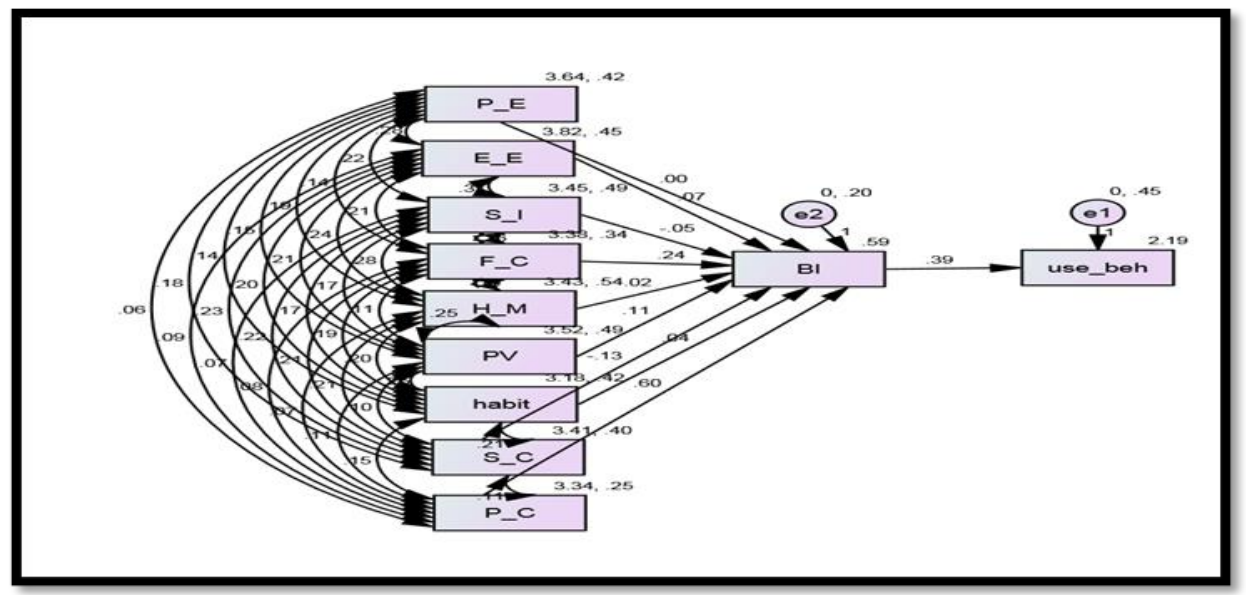

Figure3 the structural equation modeling of the research model 


\section{Conclusions}

IOT is destined to revolutionize the way in which businesses, industries, machines,

humans, and objects interact with one another (Attaran, 2017). This technology promises new opportunities for enhancing business operations, creating new products and services, and improving the quality of life for society (Attaran, 2017; Wortmann \& Flüchter, 2015). Studies have shown that 71\% of manufacturing firms have no plan to integrate IOT technologies into their processes (Brandt,2017). Studies have also found that $64 \%$ of the manufacturers were concerned about data security, and $19 \%$ were concerned about data privacy (WEFORUM, 2015). The goal of this research was to gain insight into the factors that influence the adoption of IOT devices/applications in the Egyptian society, as an example of a developing country, as well as extend the UTAUT2 model by the security concern and privacy concern variables. The problem addressed by this study is the gap in knowledge regarding the relationship between user concerns about security concern and privacy concern and their intentions to adopt IOT technologies (Attaran, 2017; Lee \& Lee, 2015). The lack of understanding of these relationships has made it difficult for organizations and their stakeholders to make informed decisions about their involvement in the development of, or investment in, IOT technologies (Krotov, 2017; Manyika et al., 2015). The purpose of this quantitative correlational study was to determine the extent to which security and privacy concerns and other factors predict users' intentions to adopt IOT technologies in Egypt. This framework contributes to the body of knowledge by extending UTAUT2.

The data analyses in this study revealed that the relationships between security concerns and user intentions were significant and that security concerns significantly predicted user intentions. The data also indicated that Facilitating Conditions (FC) and Effort Expectancy (EE) were significant to user intention to use IOT technologies while other factors not, this aligned with the fact of little knowledge of new innovation technologies in the developing countries.

\section{Limitations and direction for future research}

online surveys have a known history of response bias, and that was a concern in this study. Online surveys did not allow for a repeat of the data collection or for a follow-up with the participants if data collection errors occurred (Rice et al., 2017). The findings are not generalizable and may not reflect other counties or other geographical locations. The moderated factors of age, gender and experience is not considered in the study.

As a result, the answers provided can be assumed to be based on the current general knowledge of IOT technologies, A longitudinal study of the same, or similar sample population may show trending results that differ over time, as future research recommendations, this study suggests additional research to investigate the factors that may explain the unexplained variations in user intentions, such as technology immaturity, standardization, and government regulation.

\section{References}

Herold, R. (2015). The criticality of security on the Internet of Things. ISACA Journal, 6.

Bojanova, I., Hurlburt, G., \& Voas, J. (2014). Imagineering an Internet of anything. Computer, 47(6), $72-77$. https://doi.org/10.1109/MC.2014.150.

Abdel-Basset, Mohamed \& Manogaran, Gunasekaran \& Mohamed, Mai \& Rushdy, Ehab (2018). Internet of things in smart education environment: Supportive framework in the decision-making process. Concurrency and Computation: Practice and Experience. 31. e4515. 10.1002/cpe.4515.

Nordrum, A. (2016). The internet of fewer things. IEEE Spectrum, 53(10), 12-13, Retrieved from https://ieeexplore.ieee.org/stamp/stamp.jsp?arnumber=7572524.

Gartner (2017). Gartner says 8.4 billion connected things will be in use in 2017, up 31 percent from 2016. Retrieved from https://www.gartner.com/en/newsroom/press- releases/2017-02-07-gartner-says-8-billionconnected-things-will-be-in-use-in-2017-up- 31-percent-from-2016

International Data Corporation (2015). Worldwide Internet of Things Forecast, 2015- 2020 (IDC\#256397). Retrieved from https://www.idc.com/getdoc.jsp?containerId=US256397.

Lueth, K. L. (2018). State of the IoT 2018: Number of IoT devices now at 7B - Market accelerating. Retrieved from https://iot-analytics.com/state-of-the-iot-update-q1-q2-2018number-of-iot-devices-now-7b/

Kaki, A. H. (2018). Global IoT market to reach $\$ 318$ billion by 2023: Global Data. Retrieved from https://iot.electronicsforu.com/content/biz-trends/global-iot-market-to-reach-318-billionby-2023-globaldata/ 
Venkatesh, Viswanath and Thong, James Y.L. and Xu, Xin, Consumer Acceptance and Use of Information Technology: Extending the Unified Theory of Acceptance and Use of Technology (February 9, 2012). MIS Quarterly, Vol.36, No. 1, pp. 157-178, 2012, Available at SSRN: https://ssrn.com/abstract=2002388

Atzori, L., Iera, A., \& Morabito, G. (2010). The Internet of Things: A survey. Computer Networks, 54(15), $2787-2805$. https://doi.org/10.1016/j.comnet.2010.05.010

Venkatesh, Viswanath; Morris, Michael G.; Davis, Gordon B.; and Davis, Fred D. 2003. "User Acceptance of Information Technology: Toward a Unified View," MIS Quarterly, (27: 3).

Ammirato, S., Sofo, F., Felicetti, A.M. and Raso, C., 2018. A methodology to support the adoption of IoT innovation and its application to the Italian bank branch security context. European Journal of Innovation Management.

Alshehri, Mohammed \& Drew, Steve \& AlGhamdi, Rayed. (2013). Analysis of Citizens Acceptance for E-government Services: Applying the UTAUT Model.

Thomas, Troy \& Singh, Lenandlar \& Gaffar, Kemuel. (2013). The Utility of the UTAUT Model in Explaining Mobile Learning Adoption in Higher Education in Guyana. International Journal of Education and Development using ICT.

Sundaravej. (2005). Empirical Validation of Unified Theory of Acceptance and Use of Technology Model. Retrieved from Google Scholar:

https:/ / www.google.nl/url?sa=t\&rct=j\&q=\&esrc=s\&source=web\&cd=3\&ved=0ahUKEwjKnoPNo5XKAhXFqQ4KH W8iAWAQFgg9MAI\&url=http\%3A \%2F\%2Fwww.umsl.edu \%2F sundaravejf $\% 2 F I S 7894 \% 2 F E m p i r i c a l V a l i d a t i$ onofUnifiedTheoryofAcceptanceandUseofTechnologyModel.doc\&usg=AFQjCNFFpnz_yfnuZlCRh_O06MoWI wnO8Q

Wang, H., \& Wang, S. (2010). User acceptance of mobile internet based on the unified theory of acceptance and use of technology: Investigating the determinants and gender differences. Social Behavior and Personality: an international journal, 415- 426.

AbuShanab, \& Pearson. (2007). Internet banking in Jordan: The unified theory of acceptance and use of technology (UTAUT) perspective. J. Journal of Systems and Information Technology, 78-97.

Cheng, Song, \& Qian. (2008). Customer acceptance of Internet banking: Integrating trust and quality with UTAUT Model. Service Operations and Logistics, and Informatics, 383-388.

De Hoog. (2014). Het toepassen van het Technology Acceptance Model bij nieuwe betaalmethoden voor openbaar vervoer. Amsterdam: Universiteit van Amsterdam - Faculteit der Natuurwetenschappen, Wiskunde en Informatica.

Spil, \& Schuring. (2006). E-health systems diffusion and use. In Spil, \& Schuring, E-health systems diffusion and use. Idea Group

Alshehri, Mohammed \& Drew, Steve \& Alhussain, Thamer \& AlGhamdi, Rayed. (2012). The Effects of Website Quality on Adoption of E-Government Service: An Empirical Study Applying UTAUT Model Using SEM.

Thomas, Troy \& Singh, Lenandlar \& Gaffar, Kemuel. (2013). The utility of the UTAUT model in explaining mobile learning adoption in higher education in Guyana. International Journal of Education and Development Using ICT. 9. 71-87.

Gefen, Karahanna, \& Straub. (2003). Trust and TAM in online shopping: an integrated model. Journal MIS Quarterly archive Volume 27, 51-90.

Min, Ji, \& Qu. (2008). Mobile Commerce User Acceptance Study in China: A Revised UTAUT Model. Tsinghua Science and Technology, 257-264.

Lekitlane. (2015). UTAUT, green Values and affective factors that lead to the intention to adopt the Urban RetreatTM carpet in employees. A research project submitted to the Faculty of Humanities, Johannesburg: University of the Witwatersrand, Johannesburg.

El-Masri, Mazen \& Tarhini, Ali. (2017). Factors affecting the adoption of e-learning systems in Qatar and USA: Extending the Unified Theory of Acceptance and Use of Technology 2 (UTAUT2). Educational Technology Research and Development. 65.1-21. 10.1007/s11423-016-9508-8.

Tak, Preeti \& Panwar, Savita. (2017). Using UTAUT 2 model to predict mobile app-based shopping: evidence from India. Journal of Indian Business Research. 9. 00-00. 10.1108/JIBR-11-2016-0132.

Yuan, Shupei \& Ma, Wenjuan \& Kanthawala, Shaheen \& Peng, Wei. (2015). Keep Using My Health Apps: Discover Users' Perception of Health and Fitness Apps with the UTAUT2 Model. Telemedicine journal and e-health: the official journal of the American Telemedicine Association. 21. 10.1089/tmj.2014.0148.

Macik, Radoslaw. (2017). The Adoption of The Internet of Things by Young Consumers - an Empirical Investigation. Economic and Environmental Studies. 17.363-388. 10.25167/ees.2017.42.13.

Kim, Yonghee \& Choi, Byeongmoo \& Choi, Jeongil. (2015). A Study on the Successful Adoption of IoT Services: Focused on iBeacon and Nearby. Journal of the Korea society of IT services. 14. 217-236. 10.9716/KITS.2015.14.1.217. 
Hsu, Chin-Lung \& Lin, Judy. (2016). Exploring Factors Affecting the Adoption of Internet of Things Services. Journal of Computer Information Systems. 58. 1-9. 10.1080/08874417.2016.1186524.

Bunmi Samuel. (2018). Examining Trust as a Predictor of Adopting Federated Identity Management in U.S. Business

Attaran, M. (2017). The Internet of Things: Limitless opportunities for business and society. Journal of Strategic Innovation and Sustainability, 12(1), 10-29. Retrieved from https://www.researchgate.net/publication/314089633_The_Internet_of_Things_Limitless_Opportunities_for_ Business_and_Society.

Wortmann, F., \& Flüchter, K. (2015). Internet of Things: Technology and value added. Business and Information Systems Engineering, 57(3), 221-224. doi:10.1007/s12599-015-0383-3

Manyika, J., Chui, M., Bission, P., Woetzel, J., Dobbs, R., Bughin, J., \& Aharon, D. (2015). The Internet of Things: Mapping the value beyond the hype. Mckinsey Global Institute, 1-131. Retrieved from

https://www.mckinsey.com/search?q=internet $\% 20$ of\%20things\%20mapping $\% 20$ the $\% 20$ value $\% 20$ beyond $\% 20$ the $\% 20$ hype

Brandt, J. R. (2017). What a difference a year make: Manufacturers around the world are nowprofiting from the IoT (Are you?). The MPI Group, 1-13. Retrieved from http://mpigroup.com/product/profiting-internet-things-2

World Economic Forum. (2015). Industrial Internet of Things: Unleashing the potential of connected products and services, 135. Retrieved from http://www3.weforum.org/docs/WEFUSA_IndustrialInternet_Report2015.pdf

Krotov, V. (2017). The Internet of Things and new business opportunities. Business Horizons, 60(6), 831-841. doi: 10.1016/j.bushor.2017.07.009

Bansal, B., \& Rana, S. (2017). Internet of Things: Vision, applications, and challenges. International Journal of Engineering Trends and Technology, 47(7), 380-384. Retrieved from http://www.ijettjournal.org

Lee, I., \& Lee, K. (2015). The Internet of Things (IoT): Applications, investments, and challenges for enterprises. Business Horizons, 58(4), 431-440. doi: 10.1016/j.bushor.2015.03.008 